\title{
Preparation of Surface-Modified Nano Zinc Sulfide/Polyurethane Inorganic-Organic Transparent Coating and Its Application in Resin Lens
}

\author{
Weiping Du ${ }^{1,+}$, Yingying Ding ${ }^{1,+}$, Yang Zhang ${ }^{1}$ and Huifang Chen ${ }^{1,2, *}$ \\ 1 Department of Composite Materials, College of Materials Science and Engineering, Donghua University, \\ Shanghai 201620, China; duweiping@dhu.edu.cn (W.D.); ding2190488@163.com (Y.D.); \\ yangzhang1221@163.com (Y.Z.) \\ 2 State Key Laboratory for Modification of Chemical Fibers and Polymer Materials, Donghua University, \\ Shanghai 201620, China \\ * Correspondence: hfchen@dhu.edu.cn \\ + These authors contributed equally to this article.
}

Citation: Du, W.; Ding, Y.; Zhang, Y.; Chen, H. Preparation of SurfaceModified Nano Zinc Sulfide/ Polyurethane Inorganic-Organic Transparent Coating and Its Application in Resin Lens. Coatings 2021, 11, 894. https://doi.org/ 10.3390/coatings11080894

Received: 21 June 2021

Accepted: 21 July 2021

Published: 26 July 2021

Publisher's Note: MDPI stays neutral with regard to jurisdictional claims in published maps and institutional affiliations.

Copyright: (c) 2021 by the authors. Licensee MDPI, Basel, Switzerland. This article is an open access article distributed under the terms and conditions of the Creative Commons Attribution (CC BY) license (https:/ / creativecommons.org/licenses/by/ $4.0 /)$.

\begin{abstract}
The surface modified hydrophilic zinc sulfide nano powder was prepared by hydrothermal method, and the corresponding zinc sulfide/polyurethane organic-inorganic composite transparent coating via in-situ polymerization. The structure of ZnS Nanoparticles and organic-inorganic composite coating were characterized by Infrared Spectroscopy, X-Ray Diffraction, Laser Particle Size Analyzer and Scanning Electron Microscopy. The optical properties were measured by UltravioletVisible spectrophotometer and ellipsometry. The results show that the monodisperse hydrophilic nano zinc sulfide powder with a particle size of about $70 \mathrm{~nm}$ can be obtained by thioglycolic acid (TGA) modification, which has good compatibility with waterborne polyurethane. Nano zinc sulfide increased the refractive index of the coating significantly and the refractive index of the coatings could be controlled in the region of 1.46-1.71 organic-inorganic composite coating by adding ZnS. When the amount of nano $\mathrm{ZnS}$ added was 30\%, the refractive index of the hybrid coating can reach 1.71, and the transmittance was more than $90 \%$. The cured coatings were smooth and no agglomeration between nano $\mathrm{ZnS}$ particles could be found. After application on the surfaces of resin lens, the coatings presented better impact resistance, which indicated that the coating has application prospects in the field of fine processing of lens' surfaces.
\end{abstract}

Keywords: nano zinc sulfide; polyurethane; in-situ polymerization; coating; resin lens

\section{Introduction}

Resin materials are widely used in optics, aviation, transportation, construction and other fields. Because of their light weight and excellent optical performance, high refractive resin lenses are more and more popular. In order to improve the service life of the optical resin lens, a functional coating on the surface has become a common method adopted by lens enterprises [1,2]. The organic-inorganic composite coating takes organic matter as the matrix component and inorganic nanoparticles as the reinforcement component. By adjusting the proportion, an organic-inorganic composite functional coating with both hardness and flexibility can be prepared. Clément Sanchez et al. [3] have studied organic-inorganic hybrid materials in detail, including their classification, composition, mechanism and wide application in optics, electronics, biology, medicine, for example, as membranes and separation devices, functional smart coatings, fuel and solar cells, sensors, etc. Qian et al. [4] controlled the aggregation of inorganic colloid particles by polymerization and ultrasonic vibration. Super-hydrophobicity and transparency of the coating can be controlled by adjusting the initial concentration of monomer and the size of aggregates in the sol-gel. Thus, super-hydrophobicity and a high transparency coating can be simultaneously achieved. Salleh et al. [5] prepared ultraviolet (UV) curable acrylate modified by nano silica. The 
test showed that the material has high transparency, high scratch resistance and high wear resistance. Sangermano et al. [6] added zirconia, modified by methacrylic acid into acrylic resin, to initiate polymerization and prepared organic-inorganic composite optical film. The result shows that the addition of nano zirconia improves the heat resistance and stability of the coating. Zhou et al. [7] used an in-situ polymerization method to disperse the surface modified nano silica in acrylic resin, and mixed this with isocyanate to initiate the solidified into membrane. The hardness and scratch resistance of the coating are obviously improved after modification. Hakan et al. [8] prepared silicone modified hard coatings with methyl orthosilicate and diethylenetriamine by gel sol method. The result shows that an effectively polymerized hybrid coating rich in silica content, as realized for high tetramethyl-silo-silicate or abundant water containing sols, resulted in defective films with microcracking and adhesion problems. Pavlovsak et al. [9] prepared an organic-inorganic composite optical coating by controlling hydrolysis condensation of tetraethyl silicate in a polymethylmethacrylate, polyvinyl alcohol and vinyl acetate polymer monomer. The coating has excellent scratch resistance and high hardness. Liu et al. [10] prepared a composite optical film using methyl methacrylate and titanium dioxide by organic-inorganic synchronous polymerization. The result showed that the hybrid film had good mechanical properties, surface smoothness and high refractive index.

Inorganic nanoparticles have a series of advantages, such as excellent scratch resistance and hardness, UV resistance and high refractive index. The hybrid coatings prepared by introducing modified nanoparticles into polymer solution is an important way to improve the performance of optical lenses [11-13]. Zinc sulfide (ZnS) is one of the highly refractive index semiconductor materials (refractive index is 2.47 at $625 \mathrm{~nm}$ wavelength) and the optical absorption is low in the range $400-1400 \mathrm{~nm}$, which has a significant effect on improving the refractive index of the coating $[14,15]$. Nano $\mathrm{ZnS}$ has a high refractive index and wide light transmission range in common nanoparticles. The application of nano $\mathrm{ZnS}$ to modify the optical coating can not only improve the refractive index, wear resistance and hardness of the coating, but also can enhance the density of polymers and improve transmittance, heat resistance, aging resistance, barrier property and water resistance. In the field of nanocomposite optical materials, quantum size effect is an important factor of the refractive index. It is not necessary to consider the influence of quantum size effect on the refractive index due to the Bohr exciton radius of $\mathrm{ZnS}$ is $5.5 \mathrm{~nm}$, and the size of its nanoparticles is not much smaller than $5.5 \mathrm{~nm}$. Chaudhuri et al. [16] added thioglycolic acid (TGA) to modify nano-ZnS into polyvinylpyrrolidone by in-situ polymerization to prepare high transmittance optical film with a refractive index of 1.65. H. Althues et al. [17] prepared ZnS:Mn nanoparticles by a chemical precipitation method, and an organic-inorganic composite film with a refractive index of 1.65 was prepared by polyreaction which used the in-situ polymerization method to join the methyl methacrylate.

The nanocomposite coating applied to the optical lens should have good refractive index, transparency, better impact resistance, heat resistance and thermo-optical stability. In addition, in order to prolong the service life of the material, the composite coating should be able to improve the wear resistance and toughness of the material. Polyurethane coating is used in the impact resistance of resin lenses $[18,19]$. The coating is prepared by polycondensation of hard segment isocyanate containing a urea group and amino group with polyester, polyether or other polyols [20-22]. However, rainbow lines will appear when a polyurethane coating with low refractive index is applied to a high refractive index lens substrate, which will greatly affect the quality of the lens [23]. The modification of waterborne polyurethane coating with high refractive index inorganic nano particles can significantly enhance the refractive index, as well as solvent resistance, impact resistance and anti-aging properties of the coating [24,25]. High refractive index nanocomposite optical materials are widely used in antireflection coatings, optical lenses, optical waveguides, etc. In this paper, aqueous dispersed $\mathrm{ZnS}$ nanoparticles were prepared first, with surface modification by TGA at room temperature. Then the nanoparticles were added into waterborne polyurethane and the organic-inorganic composite coatings were prepared 
by in-situ polymerization. The structure and properties of the coating and its application in resin lens were studied.

\section{Materials and Methods}

\subsection{Experimental Reagents}

The following materials were used as purchased. Zinc chloride $\left(\mathrm{ZnCl}_{2}\right.$, analytical reagent (AR)) was obtained from Sinopharm Chemical Reagent Co., Ltd. (Shanghai, China); sodium hydroxide $(\mathrm{NaOH}$, analytical reagent $\mathrm{AR})$ was obtained from Sinopharm Chemical Reagent Co., Ltd. (Shanghai, China); sodium sulfide $\left(\mathrm{Na}_{2} \mathrm{~S}\right.$, analytical reagent $\left.\mathrm{AR}\right)$ was obtained from Shanghai Lingfeng Chemical Reagent Co., Ltd. (Shanghai, China); thioglycolic acid $\left(\mathrm{C}_{2} \mathrm{H}_{4} \mathrm{O}_{2} \mathrm{~S}\right.$, analytical reagent AR) was obtained from McLean Reagent Co., Ltd. (Shanghai, China); anhydrous ethanol $\left(\mathrm{C}_{2} \mathrm{H}_{6} \mathrm{O}\right.$, analytical reagent $\mathrm{AR}$ ) was obtained from Aladdin Reagent Co., Ltd. (Shanghai, China); two component waterborne polyurethane (grade I) was obtained from SDC Technology Co., Ltd. (Irvine, CA, USA); isopropanol $\left(\mathrm{C}_{3} \mathrm{H}_{8} \mathrm{O}\right.$, analytical reagent AR) was obtained from McLean Reagent Co., Ltd. (Shanghai, China); piranha cleaning solution (grade I) was obtained from Shanghai Huiyun Chemical Co., Ltd. (Shanghai, China); deionized water was self-made.

\subsection{Preparation of Modified Nano ZnS}

The modified nano $\mathrm{ZnS}$ particles were prepared by hydrothermal method with zinc chloride as zinc source, sodium sulfide as sulfur source and TGA as surface modifier. $0.8 \mathrm{~mL}$ sodium hydroxide solution was added into the mixed solution of zinc chloride and mercapto-acetic acid, and the $\mathrm{pH}$ of the system was adjusted to 6-7. A certain proportion of sodium sulfide solution was added and continued to react for $24 \mathrm{~h}$ at $30^{\circ} \mathrm{C}$. The original solution was centrifuged on a high-speed centrifuge at $1500 \mathrm{R} / \mathrm{min}$ for $10 \mathrm{~min}$. The solid was dissolved in $50 \mathrm{~mL}$ absolute ethanol and ultrasound for $30 \mathrm{~min}$. The cleaning steps were repeated four times. The prepared nano- $\mathrm{ZnS}$ was placed in a vacuum drying oven and dried at $60^{\circ} \mathrm{C}$ for $24 \mathrm{~h}$, then it was grinded for use.

\subsection{Preparation of Zinc Sulfide/Polyurethane Transparent Coating}

In this paper, two-component waterborne polyurethane was adopted: A component was isocyanate, B component was polyol and catalyst. The modified nano-ZnS aqueous solution was added into component A. After $30 \mathrm{~min}$ of ultrasonic dispersion, 160 mesh gauze was used for vacuum filtration three times. Under the protection of nitrogen, the modified components A and B were mixed at a ratio of 0.9:1 and let stand for $10 \mathrm{~min}$. After surface cleaning, the substrates (glass slide or resin lens) were fixed by dip coater and immersed in $\mathrm{ZnS} /$ polyurethane composite coating solutions. The substrates were drawn at a rate of $1 \mathrm{~cm} / \mathrm{min}$ after $5 \mathrm{~min}$. They were dried at room temperature for $24 \mathrm{~h}$ and then heated up to $60^{\circ} \mathrm{C}$ at a heating rate of $0.25^{\circ} \mathrm{C} / \mathrm{min}$ in an oven. After curing for $2 \mathrm{~h}$, the transparent coating was obtained.

\subsection{Structure Test and Characterization}

The structure of the surface modified nano-ZnS and composite coating were characterized by Nicolet NEXUS-670 FT-IR Raman spectrometer (Thermo Nicolet Corporation, Madison, WI, USA). The crystal structure of ZnS powder was analyzed by Bruker D2 phaser powder X-ray diffractometer (Bruker Daltonics, Karlsruhe, Germany). The particle size and potential of the aqueous dispersed nano-ZnS were measured by Malvern ZS particle analyzer (Malvern Instruments, Westborough, MA, USA). HITACHI s-4800 field emission Scanning Electron Microscopy (SEM) (Hitachi, Tokyo, Japan) was used to observe the coatings' section structure. The surface morphology of the coating was observed by Agilent 5500 atomic force microscope (Agilent Technologies, Chandler, AZ, USA). 


\subsection{Performance Characterization of ZnS/Polyurethane Transparent Coating}

The transmittance of the cured coating was measured by Lambda 950 UV-Vis spectrophotometer (Perkin Elmer, Waltham, MA, USA). The refractive index of the coating was measured by M-2000UI ellipsometry from the J.A. Woollam company (Lincoln, NE, USA) in the wavelength range $300-800 \mathrm{~nm}$ and at a $65^{\circ}$ incident angle. Pencil hardness of the coating was measured according to GB/T6739-2006 [26]. The impact resistance, water resistance, alkali resistance, extreme temperature resistance and adhesion performance of the coatings on lenses were tested according to QB/T2506-2017 [27], GB/T1733-1993 [28], GB/T9265-2009 [29] and GB/T9286-1998 [30], respectively.

\section{Results}

\subsection{Preparation of Surface Modified Nano-ZnS}

The effects of modifier content and reaction temperature on the preparation process of $\mathrm{ZnS}$ nanoparticles were studied to prepare well dispersed nanoparticles. Five experiments were carried out at $30^{\circ} \mathrm{C}$ with the molar ratio of $\mathrm{Zn} / \mathrm{TGA}$ being 1:0, 1:1, 1:2, 1:2.5 and 1:3, respectively. The solution concentration was $0.4 \mathrm{~mol} / \mathrm{L}$ and the molar ratio was 0.9 . The structure of the samples was characterized by XRD, as shown in Figure 1. It can be seen that the nano-ZnS prepared by hydrothermal method had a complete crystal structure. All samples display the same patterns as sphalerite $\mathrm{ZnS}$, due to $2 \theta$ characteristic diffraction peaks at $28.7^{\circ}, 47.7^{\circ}$ and $56.6^{\circ}$, respectively. With an increased amount of TGA, the width of diffraction peak increased, while the strength and particle size decreased. This is because the adding of TGA destroyed the crystal integrity of nano-ZnS and made the crystallinity decrease. Moreover, with the increase of TGA, the dispersion of particle size became more obvious. The spectral lines of diffraction peaks with different particle sizes overlapped, resulting in the broadening of peaks.

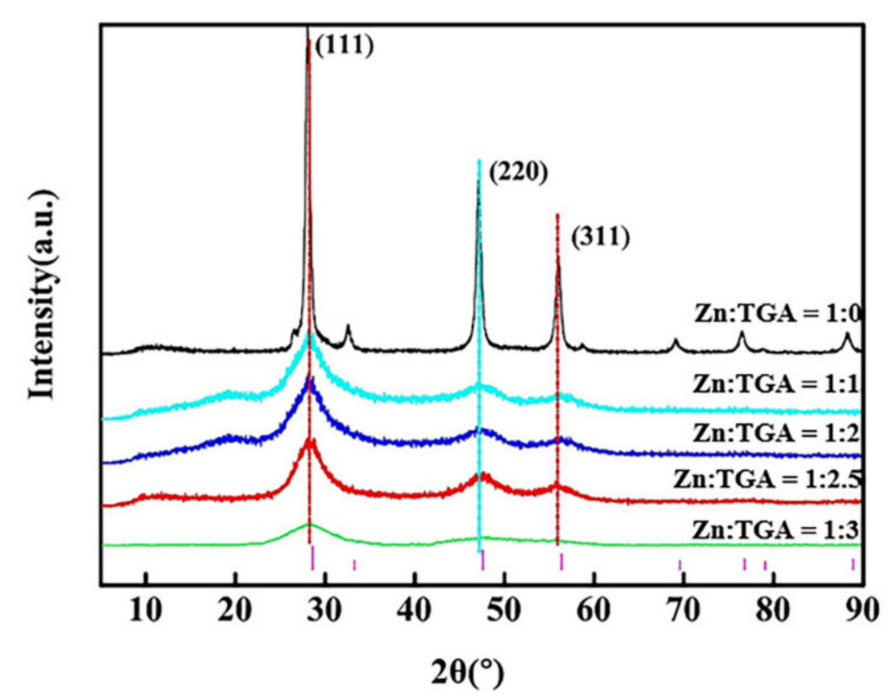

Figure 1. X-ray diffraction pattern of nano-ZnS prepared with different amounts of TGA.

The grain size could be calculated by Scherrer formula—Equation (1) (select (111) crystal plane for calculation) [31], as shown in Table 1.

$$
\mathrm{d}=\mathrm{k} \lambda / \beta \cos \theta
$$

where the constant $\mathrm{k}$ is $0.94, \beta$ is the full width of the peak at half maximum height (FWHM), $\mathrm{d}$ is the average diameter of the crystallite, and $\lambda$ represents the wavelength of the incident radiation. 
Table 1. Grain size and dispersion of modified nano-ZnS.

\begin{tabular}{cccccc}
\hline Sample & Half Width $\left.\mathbf{(}^{\circ}\right)$ & $\begin{array}{c}\text { Grain Size } \\
(\mathbf{n m})\end{array}$ & $\begin{array}{c}\text { Zeta Potential } \\
(\mathbf{m} \mathbf{)})\end{array}$ & Dispersity & $\begin{array}{c}\text { Average Particle } \\
\text { Size }\end{array}$ \\
\hline Znm)
\end{tabular}

It can be seen from the calculation that the grain size was $12.72 \mathrm{~nm}$ without TGA. Adding TGA limited the growth of grains, and the grain size gradually decreased to $1.7 \mathrm{~nm}$. The zeta potential and particle size distribution of five samples in deionized water were observed, as seen in Table 1. The average particle size of nano-ZnS was $75.15 \mathrm{~nm}$ and showed a bimodal distribution in the absence of TGA. Due to the surface modification of TGA on the formation of nano-ZnS, the nano particles were evenly dispersed and the size was reduced. When $\mathrm{Zn}: \mathrm{TGA}=1: 2$, the particle size was $31.5 \mathrm{~nm}$. With further increase of TGA, the particle size increased and showed a double peak distribution, due to the aggregation of nano-ZnS caused by the bridge effect of excessive TGA.

The surface modification effect of TGA was studied by infrared spectrum, as seen in Figure 2. The $-\mathrm{OH}$ stretching vibration peak was at the range of $3600.00-3000.00 \mathrm{~cm}^{-1}$, the $-\mathrm{SH}$ stretching vibration peak was at $2567.60 \mathrm{~cm}^{-1}$, and the $-\mathrm{COOH}$ antisymmetric and symmetric stretching vibration peaks were at $1716.54 \mathrm{~cm}^{-1}$ and $1403.41 \mathrm{~cm}^{-1}$, respectively. The $-\mathrm{C}=\mathrm{O}$ expansion vibration peak was at $1293.14 \mathrm{~cm}^{-1}$, and the $-\mathrm{OH}$ in-plane bending vibration peak was at $1154 \mathrm{~cm}^{-1}$. The $-\mathrm{CS}$ characteristic peak was at the range of $800.00-600.00 \mathrm{~cm}^{-1}$. It can be seen from the infrared spectrum of the modified nano$\mathrm{ZnS}$ that the $-\mathrm{OH}$ stretching vibration peak was at $3418.28 \mathrm{~cm}^{-1}$, and the corresponding $-\mathrm{COOH}$ antisymmetric and symmetric stretching vibration peaks shifted to $1577.13 \mathrm{~cm}^{-1}$ and $1387.99 \mathrm{~cm}^{-1}, 574.90 \mathrm{~cm}^{-1}$, respectively, the peaks corresponding to the characteristic absorption peaks of nano-ZnS. -SH stretching vibration peak at $2567.60 \mathrm{~cm}^{-1}$ disappeared, showing that $-\mathrm{SH}$ had been successfully bonded with $\mathrm{ZnS}$. TGA was grafted onto the surface of nano-ZnS and the surface was modified effectively, so that nano-ZnS could be stably dispersed in aqueous solution.

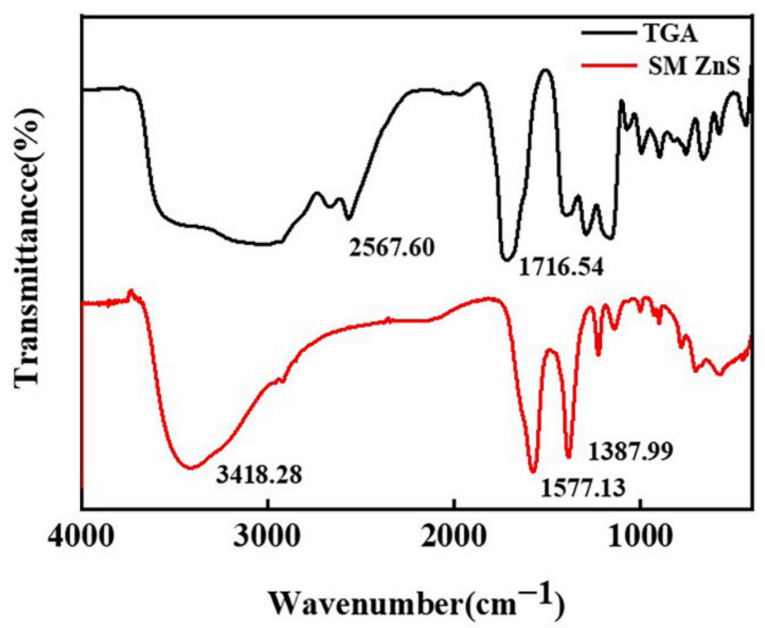

Figure 2. Infrared spectrum of surface modified nano-ZnS.

The effect of hydrothermal temperature on the morphology of ZnS particles was studied. The concentration of the reaction solution was $0.40 \mathrm{~mol} / \mathrm{L}$, the molar ratio of $\mathrm{Zn} / \mathrm{TGA}$ was 1:2, the molar ratio of $\mathrm{Zn} / \mathrm{S}$ was 0.9 , and the reaction temperature was set at $30^{\circ} \mathrm{C}, 60^{\circ} \mathrm{C}$ and $90^{\circ} \mathrm{C}$, respectively. The morphological section was observed by SEM, 
as shown in Figure 3. The prepared nanoparticles distributed uniformly and no obvious agglomeration could be found. It can be seen from the electron micrograph that, with the increase of temperature, the shape of nanoparticles changed obviously, from quasi-circular structure to hexagonal sheet structure. This is due to the fact that the TGA was grafted onto the nano-ZnS, which made the grains grow, and there were many twins and dislocations in the grains. With the increase of temperature, the grains inside the particles grew into polycrystalline aggregates. The mutual exclusion of the hydrophilic groups of grafting particles with TGA results in the crystal nucleus of wurtzite structure, and finally the irregular hexagonal sheet structure was formed [32]. At $90{ }^{\circ} \mathrm{C}$, the size of hexagonal sheet nano-ZnS was about $70 \mathrm{~nm}$, which had better heat stability.

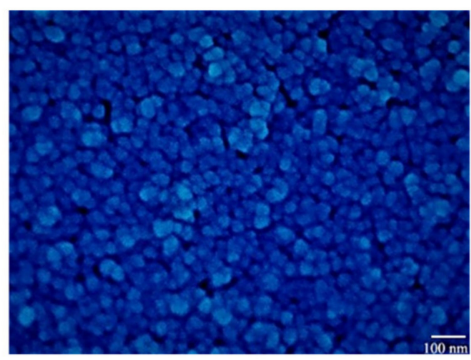

(a)

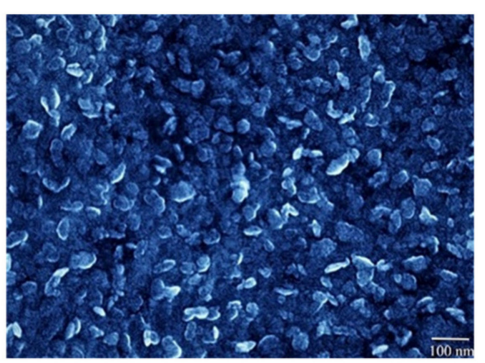

(b)

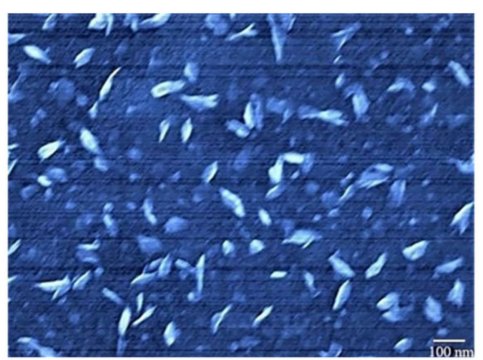

(c)

Figure 3. Electron micrograph of nano-ZnS prepared at different heating temperatures: (a) The samples prepared at $30{ }^{\circ} \mathrm{C}$; (b) The samples prepared at $60{ }^{\circ} \mathrm{C}$; (c) The samples prepared at $90{ }^{\circ} \mathrm{C}$.

\subsection{Waterborne Polyurethane Coating Modified by Nano-ZnS}

The prepared $70 \mathrm{~nm} \mathrm{ZnS}$ was added to the two-component waterborne polyurethane via in-situ polymerization and five experiments were carried out with a nano-ZnS content of $10 \%, 15 \%, 20 \%, 25 \%$ and $30 \%$, respectively. The above coating was put onto the silicon substrate by spin coating, and the refractive index was measured after curing, as shown in Figure 4.

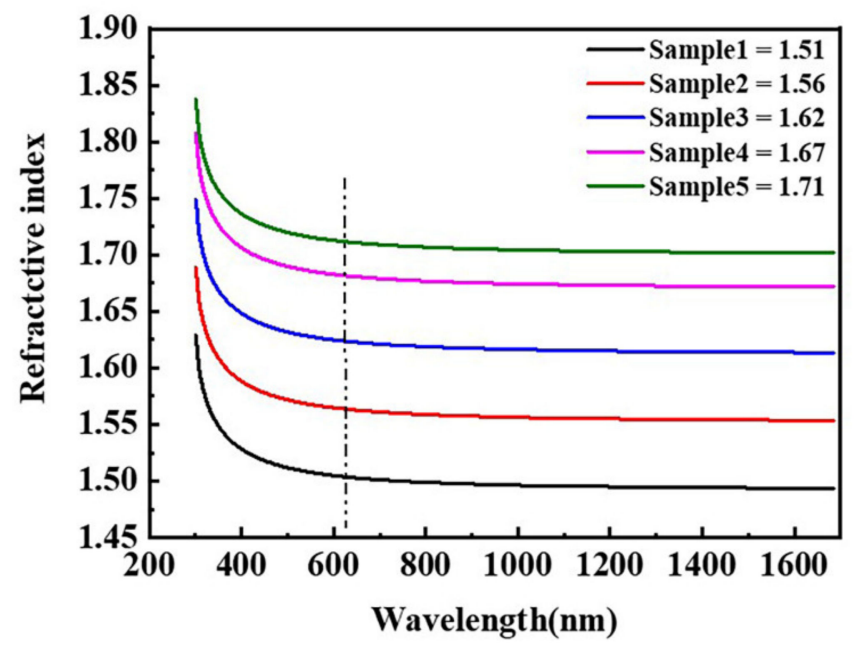

Figure 4. Refractive index of composite coating with different nano-ZnS content.

The refractive index of waterborne polyurethane coating was only 1.46 . This indicates that the refractive index increased from 1.51 to 1.71 (at the wavelength of $625 \mathrm{~nm}$ ) with the increase in $\mathrm{ZnS}$ content. This is due to the significantly improved refractive index of nano-ZnS, going up to 2.47 .

The transmittance of nano-ZnS/waterborne polyurethane composite coating with different contents was studied to explore the influence of nano-ZnS on the optical properties of the coating with a $\mathrm{ZnS}$ content of $0 \%, 10 \%, 15 \%, 20 \%, 25 \%$ and $30 \%$, respectively, and 
the results are shown in Figure 5. It can be seen that the transmittance was $93.6 \%$ without nano-ZnS by analyzing the different transmittances of the coating. The transmittance reduced slightly with the increase of nano- $\mathrm{ZnS}$, but the transmittance of all samples was higher than $90 \%$. This indicates that the nano-ZnS/polyurethane composite coating has higher transmittance.

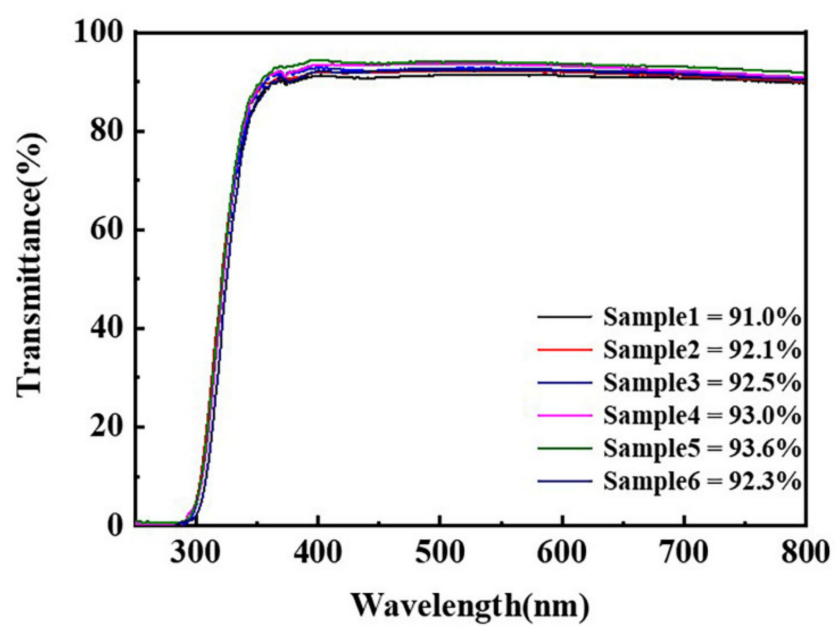

Figure 5. Light transmittance of composite coating with different nano-ZnS content. The amount of nano-ZnS added to sample 1 in the figure accounts for $30 \%$, sample 2 for $20 \%, 3$ for $15 \%$, 4 for $10 \%$, 5 for blank, 6 for $25 \%$ of the content of waterborne polyurethane.

The hardness of the coating with different contents of nano-ZnS on the glass substrate was measured, as shown in Figure 6. According to the tests, the hardness of waterborne polyurethane coating was lower, due to the higher content of flexible polymer segments. The hardness of the coating increased from $6 \mathrm{~B}$ to HB with the increase of nano- $\mathrm{ZnS}$ content. The reason is that nano- $\mathrm{ZnS}$ has higher hardness by itself. The modified nano zinc sulfide can provide active sites to form chemical bonds between the isocyanate groups of the PU chains and hydroxyl groups on the nano particles, which increased the hardness of the coating [33]. The addition of nano zinc sulfide made the composite coating retain the impact resistance of the waterborne polyurethane coating and increased the hardness, to some extent, at the same time.

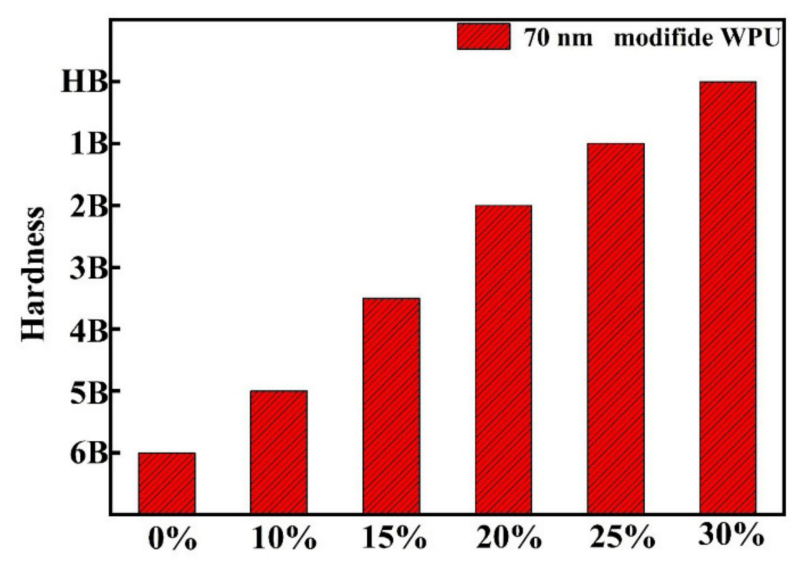

Figure 6. Hardness of composite coating with different nano-ZnS content.

The particle size distribution of the composite coating (a) and the cross-section SEM (b) of the solidified coating were studied to further research the distribution of nano$\mathrm{ZnS}$ in composite coating, as shown in Figure 7. From the size and potential tests, we know that the two-component composite aqueous polyurethane solution showed a single 
peak distribution, the average particle size was about $80 \mathrm{~nm}$, and there was no settling phenomenon. The average Zeta potential of the coating was $46.3 \mathrm{mV}$, which indicates that the coating had good stability. The section morphology of the coating was observed after quenching in liquid nitrogen. It can be seen from the SEM photograph that the section of the material was smooth without serious cracks. Nano-ZnS was evenly distributed on the section, the particle size was about $70 \mathrm{~nm}$, and there was no significant aggregation. This is due to the fact that the nano-ZnS modified by TGA was grafted with organic chain segments, which prevented the agglomeration of nano particles and had a good dispersing effect.

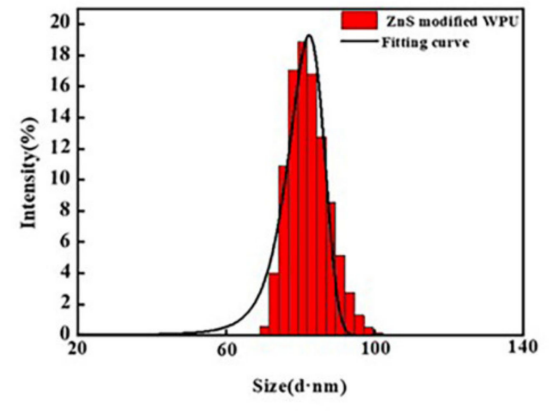

(a)

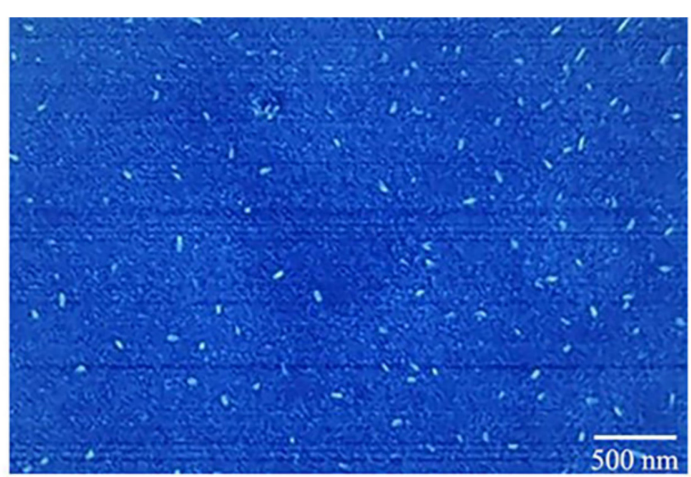

(b)

Figure 7. (a) Distribution of nano-ZnS in composite coating (nano-ZnS content is 25\%); (b) The cross-section SEM of the coating.

The waterborne polyurethane with different nano $\mathrm{ZnS}$ content was coated on the silicon substrate. The surface morphology of the coating was characterized by Atomic Force Microscopy (AFM), and the surface roughness was analyzed, as shown in Figures 8 and 9. The fluctuation of the coating changed at the range of 10-45 $\mathrm{nm}$ and the roughness increased with the increase in nano $\mathrm{ZnS}$ content, as shown in Figure 8. The average roughness of the coating was $3.47 \mathrm{~nm}$ when the nano $\mathrm{ZnS}$ content was $10 \%$. When the content of nano $\mathrm{ZnS}$ increased to $30 \%$, the roughness of the coating increased to $6.7 \mathrm{~nm}$, as shown in Figure 9. With the increase of nano $\mathrm{ZnS}$ content, the waterborne polyurethane component in the coating decreased, which made the network cross-linking structure of the coating more compact; the average roughness of the coating increased significantly and the transmittance decreased.

The fluctuation of the coating changed at the range of 10-45 $\mathrm{nm}$ and the roughness increased with the increased of nano $\mathrm{ZnS}$ content, as shown in Figure 8. The average roughness of the coating was $3.47 \mathrm{~nm}$ when the nano $\mathrm{ZnS}$ content was $10 \%$. When the content of nano $\mathrm{ZnS}$ increased to $30 \%$, the roughness of the coating increased to $6.7 \mathrm{~nm}$, as shown in Figure 9. With the increase of nano $\mathrm{ZnS}$ content, the waterborne polyurethane component in the coating decreased, the average roughness of the coating increased significantly and the transmittance decreased. 

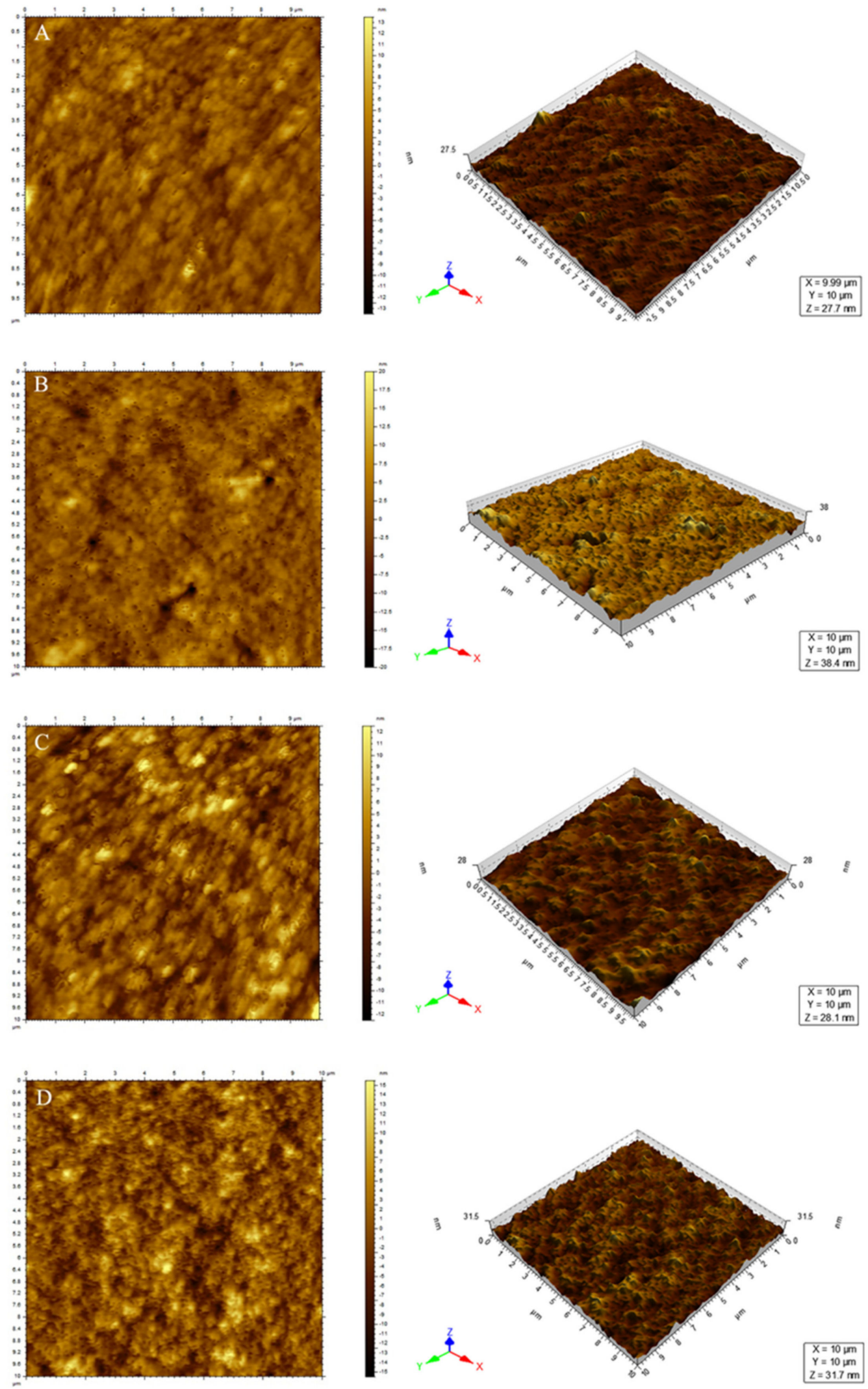

Figure 8. Cont. 

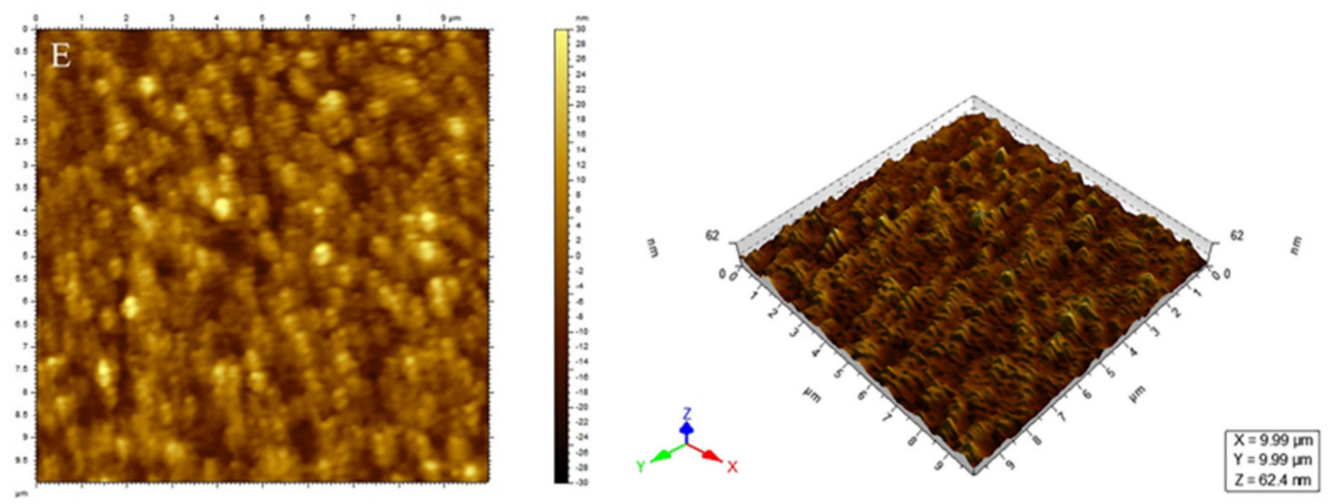

Figure 8. AFM of the coating with different nano $\mathrm{ZnS}$ content (Note: (A-E) in turn correspond to the nano $\mathrm{ZnS}$ content at $10 \%, 15 \%, 20 \%, 25 \%, 30 \%)$.

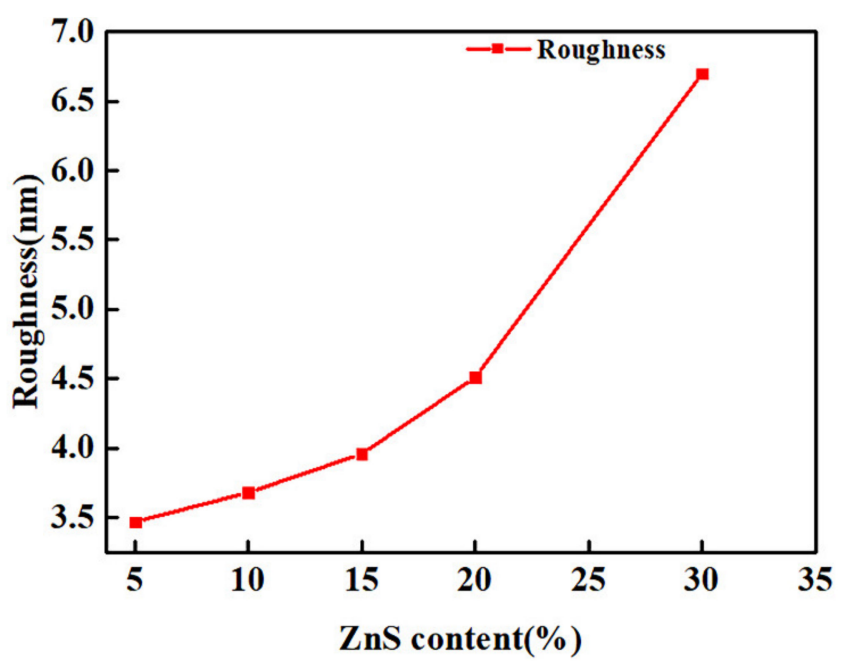

Figure 9. Roughness of coatings with different nano-ZnS content.

\subsection{Application of ZnS/Polyurethane composite Coating on Resin Lens}

The application of nano-ZnS/polyurethane composite coating was studied with ZnS addition contents of $10 \%, 15 \%, 20 \%, 25 \%$ and $30 \%$, respectively. The impact resistance of samples was tested after film curing, as shown in Figure 10. A steel ball with a mass of $16 \mathrm{~g}$ fell freely from a height of $1.27 \mathrm{~m}$ and impacted the convex surface of the lens. By observing whether the lens was cracked or broken, the impact resistance of the lens could be judged. From Figure 10, we know that the composite coating had good impact resistance and there were no cracks, because of a large number of flexible segments in polyurethane molecules linking to each other, which providing resin lenses with excellent impact resistance.

The extreme temperature tests and water resistance tests of the composite coating were carried out, as shown in Figure 11. This indicates that the composite coating had better temperature resistance and water resistance. The coating had no cracks, shedding and blistering, and the addition of nano-ZnS did not damage the molecular structure of waterborne polyurethane.

The alkali resistance tests were carried out as shown in Figure 12. The composite coating had good alkali resistance without cracks and shedding phenomenon with the content of $\mathrm{ZnS}$ at less than $30 \%$. However, when the content reached $30 \%$, the coating cracked. This is mainly because the high content of nano particles made the cross-linking density of the coating decrease, so that the alkali resistance decreased. 


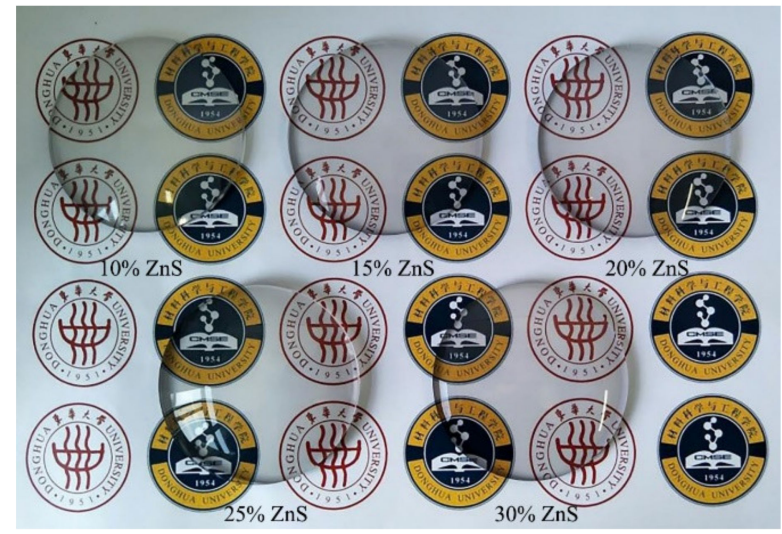

Figure 10. Impact resistance diagram of composite coating (Note: the addition amount of $\mathrm{ZnS}$ is $10 \%$, $15 \%, 20 \%, 25 \%, 30 \%$, respectively).

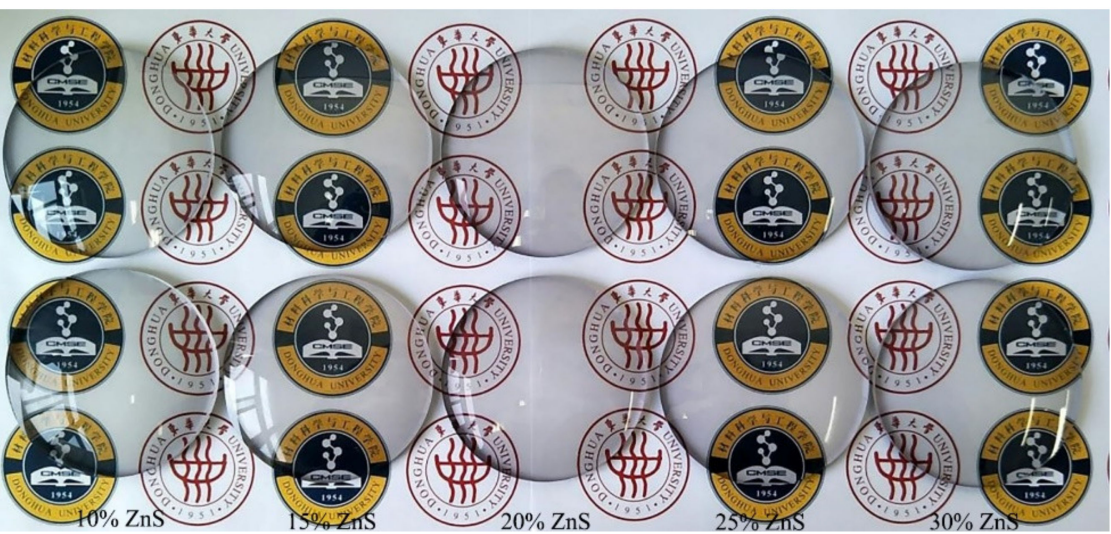

Figure 11. High and low temperature resistance test (up) and water resistance test (down) of composite coating (Note: the addition amount of $\mathrm{ZnS}$ is $10 \%, 15 \%, 20 \%, 25 \%$ and $30 \%$, respectively).

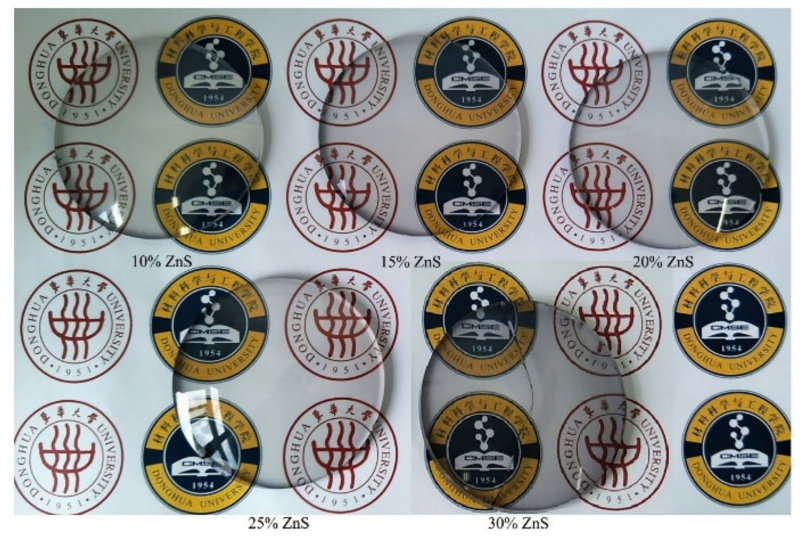

Figure 12. Alkali resistance test of composite coating (Note: the addition amount of $\mathrm{ZnS}$ is $10 \%, 15 \%$, $20 \%, 25 \%$ and $30 \%$, respectively).

The adhesion was also tested, as shown in Figure 13. The composite coating had better adhesion with no shedding, reaching the optimal level of 0 when the content of $\mathrm{ZnS}$ was less than $30 \%$. When the content reached 30\%, the edge of the incision crossing slightly fell off, the falling area was less than $5 \%$, and the adhesion level was 1 . According to the application test of the composite coating for the resin lens, when the content of ZnS was less than $30 \%$, the coating had better practicability and met the business requirements of lens manufacturers. 


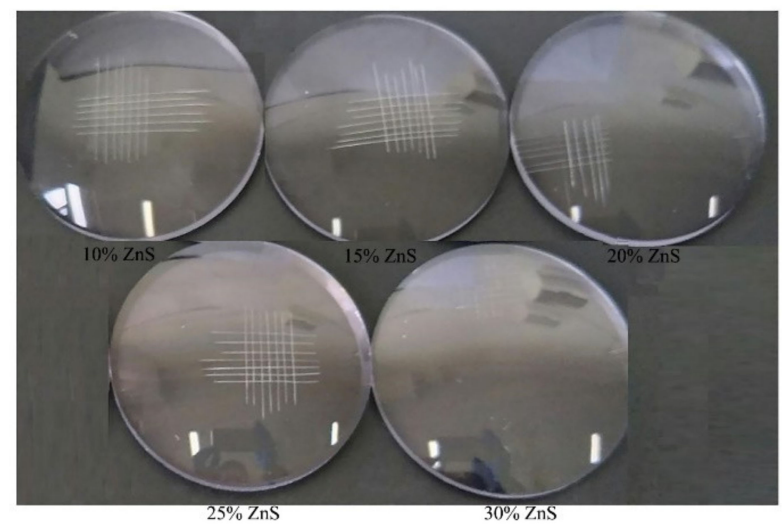

Figure 13. Coating adhesion test.

\section{Conclusions}

The hydrophilic nano-ZnS powder was prepared via one-step homogeneous precipitation with TGA as modifier. The particle size of nano-ZnS powder was $70 \mathrm{~nm}$ and the dispersibility was stable. The dispersed uniformly ZnS/polyurethane composite impact resistant coating solution was prepared via in-situ polymerization. Nano-ZnS was uniformly dispersed in waterborne polyurethane without agglomeration. Modified nano-ZnS had excellent compatibility with waterborne polyurethane. We know from the structure and performance characterizations that the refractive index (1.46-1.71) and the heat resistance of the composite coating could be significantly improved and the coating had better light transmittance $(>90 \%$ ) after the addition of nano-ZnS powder, meeting the demands of the high refractive index resin lens. The experiments showed that when the content of nano-ZnS was less than $30 \%$, the coating had excellent impact resistance, water resistance, alkali resistance and extreme temperatures resistance, and provided more effective and lasting protection for lenses, suggesting that this environmentally friendly coating with high refractive index has considerable application potential in the field of resin lens fine processing.

Author Contributions: Conceptualization, H.C.; investigation, Y.Z.; investigation, writing-original draft preparation, Y.D.; investigation, writing-review and editing, W.D. All authors have read and agreed to the published version of the manuscript.

Funding: This research was funded by the National Key Research and Development Program of China, grant number 2016YFB0302300. The APC was funded by 2016YFB0302300.

Institutional Review Board Statement: Not applicable.

Informed Consent Statement: Not applicable.

Data Availability Statement: Data sharing is not applicable to this article.

Conflicts of Interest: The authors declare no conflict of interest.

\section{References}

1. Murahara, M.; Yabe, T.; Uchida, S.; Yoshida, K.; Okamoto, Y. Anti-reflective and waterproof hard coating for high power laser optical elements. AIP Conf. Proc. 2006, 830, 457-465. [CrossRef]

2. Hock, M.; Schäffer, E.; Döll, W.; Kleer, G. Composite coating materials for the moulding of diffractive and refractive optical components of inorganic glasses. Surf. Coat. Technol. 2003, 163, 689-694. [CrossRef]

3. Sanchez, C.; Julian-Lopez, B.; Belleville, P.; Popall, M. Applications of hybrid organic-inorganic nanocomposites. J. Mater. Chem. 2005, 15, 3559-3592. [CrossRef]

4. Xu, Q.F.; Wang, J.N.; Sanderson, K.D. Organic-inorganic composite nanocoatings with superhydrophobicity, good transparency, and thermal stability. ACS Nano 2010, 4, 2201-2209. [CrossRef]

5. Salleh, N.G.N.; Alias, M.S.; Gläsel, H.-J.; Mehnert, R. High performance radiation curable hybrid coatings. Radiat. Phys. Chem. 2013, 84, 70-73. [CrossRef] 
6. Sangermano, M.; Voit, B.; Sordo, F.; Eichhorn, K.-J.; Rizza, G. High refractive index transparent coatings obtained via UV/thermal dual-cure process. Polymer 2008, 49, 2018-2022. [CrossRef]

7. Que, W.X.; Sun, Z.; Zhou, Y.; Lam, Y.L.; Chan, Y.C.; Kam, C.H. Optical and mechanical properties of $\mathrm{TiO}_{2} / \mathrm{SiO}_{2} /$ organically modified silane composite films prepared by sol-gel processing. Thin Solid Film 2000, 359, 177-183. [CrossRef]

8. Yavas, H.; Selçuk, C.D.; Özhan, A.S.; Durucan, C. A parametric study on processing of scratch resistant hybrid sol-gel silica coatings on polycarbonate. Thin Solid Film 2014, 556, 112-119. [CrossRef]

9. Pavlovska, I.; Malnieks, K.; Mezinskis, G.; Bidermanis, L.; Karpe, M. Hard $\mathrm{TiO}_{2}-\mathrm{SiO}_{2}$ sol-gel coatings for enamel against chemical corrosion. Surf. Coat. Technol. 2014, 258, 206-210. [CrossRef]

10. Liu, B.-T.; Li, P.-S.; Chen, W.-C.; Yu, Y.-Y. Ex situ synthesis of high-refractive-index polyimide hybrid films containing TiO ${ }_{2}$ chelated by 4-aminobenzoic acid. Eur. Polym. J. 2014, 50, 54-60. [CrossRef]

11. Bochev, B.; Yordanov, G. Room temperature synthesis of thioglycolate-coated zinc sulfide (ZnS) nanoparticles in aqueous medium and their physicochemical characterization. Colloids Surf. A Physicochem. Eng. Asp. 2014, 441, 84-90. [CrossRef]

12. Ohno, T.; Tagawa, S.; Itoh, H.; Suzuki, H.; Matsuda, T. Size effect of $\mathrm{TiO}_{2}-\mathrm{SiO}_{2}$ nano-hybrid particle. Mater. Chem. Phys. 2009, 113, 119-123. [CrossRef]

13. Soltani, N.; Saion, E.; Erfani, M.; Rezaee, K.; Bahmanrokh, G.; Drummen, G.P.C.; Bahrami, A.; Hussein, M.Z. Influence of the polyvinyl pyrrolidone concentration on particle size and dispersion of ZnS nanoparticles sythesized by microwave irradiation. Int. J. Mol. Sci. 2012, 13, 12412-12427. [CrossRef] [PubMed]

14. Fang, X.; Zhai, T.; Gautam, U.K.; Li, L.; Wu, L.; Bando, Y.; Golberg, D. ZnS nanostructures: From synthesis to applications. Prog. Mater. Sci. 2011, 56, 175-287. [CrossRef]

15. Persits, N.; Aharoni, A.; Tur, M. Quantitative characterization of ZnS: Mn embedded polyurethane optical emission in three mechanoluminescent regimes. J. Lumin. 2017, 181, 467-476. [CrossRef]

16. Chaudhuri, T.K.; Tiwari, D. Earth-abundant non-toxic $\mathrm{Cu}_{2} \mathrm{ZnSnS}_{4}$ thin films by direct liquid coating from metal-thiourea precursor solution. Sol. Energy Mater. Sol. Cells 2012, 101, 46-50. [CrossRef]

17. Althues, H.; Palkovits, R.; Rumplecker, A.; Simon, P.; Sigle, W.; Bredol, M.; Kynast, U.; Kaskel, S. Synthesis and characterization of transparent luminescent ZnS: Mn/PMMA nanocomposites. Chem. Mater. 2006, 18, 1068-1072. [CrossRef]

18. Wu, D.; Xu, H.; Qiu, F.; Yang, D. Preparation, Morphology and Properties of Waterborne-Polyurethane/Silica. Polym. Technol. Eng. 2011, 50, 498-508. [CrossRef]

19. Li, G.J.; Huang, Y.G.; Zhu, Z.Z.; Luo, W.A.; Chen, X.D. Fluorescence spectra of zinc sulfide quantum dots/polyurethane nano-composite. J. South China Univ. Technol. (Nat. Sci.) 2009, 37, 1-5. [CrossRef]

20. Balakrishnan, A.; Saha, M.C. Effect of ultrasound and strain rate on tensile behavior of neat thermoplasticpolyurethane thin films. In Proceedings of the Asme International Mechanical Engineering Congress and Exposition, Vancouver, BC, Canada, 12-18 November 2010; pp. 123-128. [CrossRef]

21. Agrawal, S.; Patidar, D.; Saxena, N. Glass transition temperature and thermal stability of ZnS/PMMA nanocomposites. Phase Transit. 2011, 84, 888-900. [CrossRef]

22. Lukosz, W.; Tiefenthaler, K. Embossing technique for fabricating integrated optical components in hard inorganic waveguiding materials. Opt. Lett. 1983, 8, 537-539. [CrossRef] [PubMed]

23. Nair, S.; Kumar, P. Molecular characterization of a lipase-producing Bacillus pumilus strain (NMSN-1d) utilizing colloidal water-dispersible polyurethane. World J. Microbiol. Biotechnol. 2007, 23, 1441-1449. [CrossRef]

24. Li, S.; Lin, M.M.; Toprak, M.S.; Kim, D.K.; Muhammed, M. Nanocomposites of polymer and inorganic nanoparticles for optical and magnetic applications. Nano Rev. 2010, 1. [CrossRef]

25. Tiefenthaler, K.; Briguet, V.; Buser, E.; Horisberger, M.; Lukosz, W. Preparation Of planar optical $\mathrm{SiO}_{2}-\mathrm{TiO}_{2}$ and $\mathrm{LiNbO}_{3}$ waveguides with a dip coating method and an embossing technique for fabricating grating couplers and channel waveguides. Thin Film Technol. I 1983, 401, 165-173. [CrossRef]

26. GB/T6739-2006 Paints and Varnishes-Determination of Film Hardness by Pencil Test; Standards Press of China: Beijing, China, 2006.

27. QB/T2506-2017 Uncut Finished Spectacle Lenses-Optical Hard Resin Lenses; China Light Industry Press: Beijing, China, 2017.

28. GB/T1733-1993 Determination of Resistance to Water of Films; Standards Press of China: Beijing, China, 1993.

29. GB/T9265-2009 Determination for Alkali Resistance of Film of-Architectural Paints and Coatings; Standards Press of China: Beijing, China, 2010.

30. GB/T9286-1998 Paints and Varnishes-Cross Cut Test for Films; Standards Press of China: Beijing, China, 1999.

31. Cheng, Z.; Meng, Y.; Zhang, B. Effect of sputtering power on the microstructure of Mg doped ZnO thin films. IOP Conf. Ser. Mater. Sci. Eng. 2020, 892. [CrossRef]

32. Xiong, Y.; Zhang, J.; Huang, F.; Ren, G.; Liu, W.; Li, D.; Wang, C.; Lin, Z. Growth and phase-transformation mechanisms of nanocrystalline CdS in $\mathrm{Na}_{2} \mathrm{~S}$ solution. J. Phys. Chem. C 2008, 112, 9229-9233. [CrossRef]

33. Wang, X.; Hu, Y.; Song, L.; Yang, H.Y.; Xing, W.Y.; Lu, H.D. In situ polymerization of graphene nanosheets and polyurethane with enhanced mechanical and thermal properties. J. Mater. Chem. 2011, 21, 4222-4227. [CrossRef] 